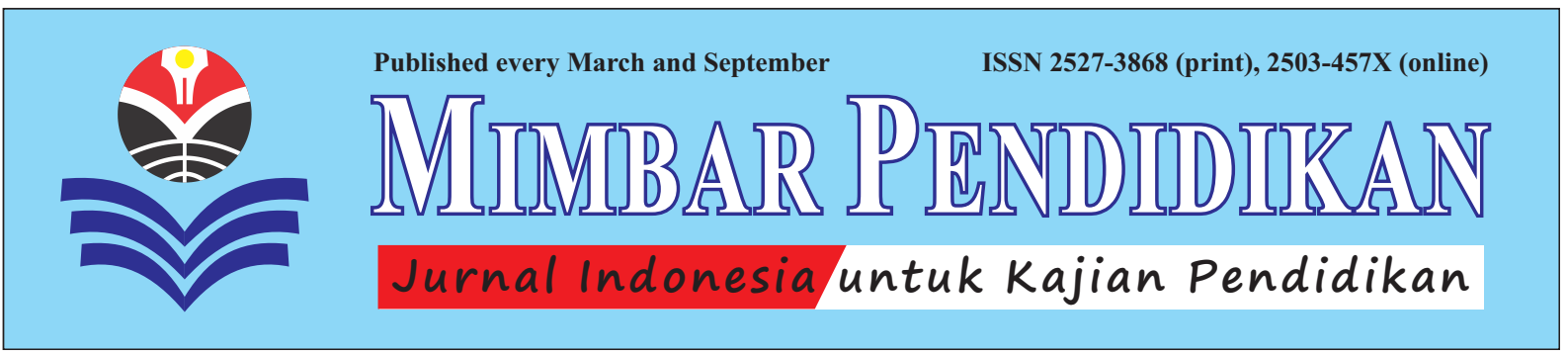

AHMAD QURTUBI

\title{
Peran Kepala Sekolah dalam Memfasilitasi Pembinaan Guru di Lingkungan Sekolah Multikultural melalui Kepemimpinan Profesional
}

\begin{abstract}
ABSTRAKSI: Kepala sekolah memiliki tanggung jawab luas dalam manajemen sekolah, mulai dari masalah kurikulum hingga akuntabilitas sekolah. Kepala sekolah juga harus memberikan bimbingan kepada guru tentang proses dan akuntabilitas dalam bidang pendidikan. Namun, perlu dicatat di sini bahwa masalah siswa juga harus dibangun melalui kepemimpinan profesional kepala sekolah untuk mengelola kualitas pendidikan. Makalah ini betujuan untuk mengidentifikasi kepemimpinan profesional kepala sekolah, yang berdampak pada kualitas pendidikan sekolah. Data dikumpulkan dengan pendekatan deskriptif-kuantitatif, kemudian dianalisis dengan menggunakan Stata Software 12. Hasil penelitian menunjukan bahwa terdapat beberapa aspek yang mempengaruhi kualitas pendidikan di SMA (Sekolah Menengah Atas) di Jakarta Selatan, yakni: kemampuan untuk mengelola siswa, manajemen keuangan, koordinasi dan pemantauan kegiatan sekolah, pengembangan guru dan siswa, konstruksi pengetahuan, dan pengurangan prasangka dalam mengembangkan budaya sekolah yang sehat.

KATA KUNCI: Kepala Sekolah; Kepemimpinan Profesional; Mentoring Guru; Manajemen Kesiswaan; Kualitas Pendidikan.
\end{abstract}

ABSTRACT: "The Roles of School Principal in Facilitating Teacher Mentoring in Multicultural Environment through Professional Leadership”. The school principal has a broad responsibility in school management, ranging from curriculum matters to school accountability. The principal also has to provide guidance to teachers about the process and accountability in educational field. But, it is important to note here that students' matters must be established through professional leadership to manage education quality. This paper intends to identify the professional leadership of principals, which impacts on the school education quality. The data were collected by employing the quantitative-descriptive approach, and were then analysed using Stata Software 12. Findings show that there are several aspects impacting the education quality of Senior High Schools in South Jakarta, namely: the ability to manage the students, financial management, coordination and monitoring of school activities, development of teachers and students, knowledge construction, and prejudice reduction in developing a healthy school culture. KEY WORD: School Principal; Professional Leadership; Teacher Mentoring; Student Management; Quality of Education.

About the Author: Dr. Ahmad Qurtubi adalah Dosen UIN (Universitas Islam Negeri) Syarif Hidayatullah di Jakarta; dan Pengelola SMK (Sekolah Menengah Kejuruan) Labschool Tangerang Raya, Jalan Raya Kp. Melayu Km.4, Bandara Soekarno-Hatta, Gank Intake, PDAM Desa Bojongrenge, Kecamatan Teluknaga, Kabupaten Tangerang, Banten, Indonesia. Alamat emel: ahmadqurtubistiatara@gmail.com

How to cite this article? Qurtubi, Ahmad. (2017). "Peran Kepala Sekolah dalam Memfasilitasi Pembinaan Guru di Lingkungan Sekolah Multikultural melalui Kepemimpinan Profesional" in MIMBAR PENDIDIKAN: Jurnal Indonesia untuk Kajian Pendidikan, Vol.2(1) March, pp.81-94. Bandung, Indonesia: UPI [Indonesia University of Education] Press, ISSN 2527-3868 (print) and 2503-457X (online).

Chronicle of the article: Accepted (September 25, 2016); Revised (January 25, 2017); and Published (March 30, 2017). 


\section{PENDAHULUAN}

Kepala sekolah memegang tanggung jawab yang luas dalam pengelolaan sekolah, mulai dari kepatuhan dan akuntabilitas sekolah hingga memberikan bimbingan kepada guru mengenai proses yang terkait dengan pelaksanaan regulasi pendidikan. Tugas kepala sekolah makin berat, dimana mereka harus memperbaiki masalah disiplin guru terkait keterlambatan, absensi, dan kekerasan yang dilakukan kepada siswa. Kepala sekolah berada pada persimpangan jalan, antara hukum dan pendidikan, dimana mereka harus mematuhi regulasi pendidikan; dan juga mengumpulkan harapan dan aturan yang diajarkan dalam lingkungan sekolah. Untuk mencapai hal itu, kepala sekolah tidak bisa bekerja sendirian, tapi harus mampu memfasilitasi guru melalui aktivitas mentoring yang sesuai dengan semangat demokrasi, pendidikan, dan akses konsultasi untuk menghadapi tantangan agar proses pendidikan dapat dikelola dengan baik (Ovando \& Trube, 2014).

Meskipun terdapat prosedur perilaku dan dukungan proses ditujukan untuk semua siswa, namun guru harus tetap konsisten untuk mengelola kualitas dalam proses dan hasil pendidikan. Namun, seringkali, kepala sekolah harus mampu mengindentifikasi elemen penting untuk meningkatkan kinerja guru di sekolah. Untuk itu, banyak sekolah telah menerapkan berbagai metode yang didasarkan pada pengelolaan harapan dan aturan bersama antara guru untuk tujuan penguatan sistem (Farisi, 2012; dan Sumarsono, 2016). Salah satu sistem yang paling umum digunakan ialah pelatihan mentoring untuk penguataan dan pendisiplinan, yang dikembangkan untuk memperbaiki proses evaluasi dan benchmark quality, sebagai strategi keterlibatan guru dan kepala sekolah dalam memperbaiki proses pendidikan (Ovando \& Trube, 2014).

Dalam proses benchmark tentang kualitas pendidikan, kepala sekolah mengambil studi kasus untuk menganalisis proses disiplin yang sering terjadi di lingkungan sekolah, baik internal dan eksternal; kemudian mengelola pertemuan pemimpin dan anggota untuk mencapai agenda keselarasan dan komunikasi dengan guru mereka. Hasilnya diperoleh evaluasi tindakan yang menjadi aturan bersama untuk memperbaiki pengajaran dan proses disiplin (Wilison, 2010; dan Sinaga, 2015).

Mengingat bahwa sekarang ini regulasi pendidikan cepat berubah, dan sekolah harus terus mematuhi persyaratan hukum dan juga kebutuhan guru dan siswa, maka kepala sekolah harus menyediakan waktu lebih banyak untuk berdiskusi dengan guru dan menyediakan kesempatan pelatihan bagi guru. Namun, untuk mengembangkan master plan dalam meningkatkan perilaku dan disiplin guru di sekolah-sekolah, yang meliputi dukungan perilaku positif, dan pemantauan harus disesuaikan dengan kapasitas dan kompetensi kepala sekolah (Soutworth, 2002; dan Rahayu, Sutama \& Narimo, 2014).

Selain itu, dalam proses mentoring, kepala sekolah perlu memperhatikan persyaratan pelatihan guru. Untuk mencapai tujuan itu perlu inventarisasi sumber daya pelatihan yang tersedia bagi sekolah, dan juga mengukur kebutuhan sekolah kedalam model master plan on mentoring (Simon \& Johnson, 2013).

Untuk menentukan pelatihan bagi guru, kepala sekolah harus mempertimbangkan kebutuhan sekolah dan juga tingkat kesanggupan belajar dari guru untuk mempromosikan disiplin dan budaya sekolah (Dagett, 2005; dan Suherman, 2016). Dalam proses mentoring tersebut, kepala sekolah perlu mengukur tingkat kontribusi guru bagi akuntabilitas sekolah dan memenuhi mandat dengan menggunakan benchmark data yang kualitas, termasuk penjadwalan dalam mengidentifikasi peningkatan kapasitas kerja guru.

Evaluasi peningkatan kapasitas guru dapat dilakukan setahun dua kali, dimana 
diperbarui sesuai kebutuhan dan harapan siswa dan orang tua. Dalam hal ini, kepala sekolah harus mampu menyeimbangkan antara persyaratan regulasi dan juga pandangan dari orang tua siswa. Orang tua siswa harus memiliki ruang untuk intervensi yang tepat dalam rangka meningkatkan kapasitas/kompetensi mengajar guru dan juga kepala sekolah. Dalam konteks ini, sekolah harus memiliki kebijakan untuk meningkatkan kualitas, dengan dukungan dari masyarakat, konsultan eksternal, dan orang tua siswa (Trezna, 2015).

Semua tindakan mentoring dibingkai dalam proses benchmarking berbasis bukti. Dengan memiliki bukti yang cukup, kepala sekolah dapat mengatasi masalah dalam lingkungan yang ilmiah dan bergerak mencapai hasil bersama (Gorton \& Schneider, 1991). Hal ini dapat dilakukan dengan menerapkan sistem informasi administrasi sekolah yang memiliki fitur penelusuran kegiatan guru dan sistem harus bekerja kongruen, yang mendukung kepala sekolah untuk memantau semua aspek di sekolah. Data sekolah harus dikelola secara akademis dan tidak sewenang-wenang dalam memutuskan sesuatu; dan tujuannya adalah untuk membentuk iklim perilaku yang mendukung prestasi belajar, bukan menghasilkan proses penghukuman dan kekerasan, baik fisik maupun verbal.

Di setiap sekolah terdapat perbedaan, baik budaya maupun norma, yang dilaksanakan oleh guru dan siswa (Maisyaroh, 2016). Oleh karena itu, proses mentoring harus bertujuan mencari arah yang mempertemukan antara guru dengan siswa, yang pada gilirannya menghasilkan intervensi tepat (Santamaría et al., 2016). Hal ini harus dimulai dari kepala sekolah sendiri untuk mengumpulkan data tentang intervensi yang menjadi praktek terbaik dan menentukan, dimana intervensi itu dalam bentuk mentoring yang akan bekerja secara efektif untuk mencapai keberhasilan.

Kepala sekolah harus membuat keputusan yang, baik secara langsung dan tidak langsung, mempengaruhi keberhasilan sekolah (Uben \& Hughes, 1992). Tolok ukur kualitas dan setting kualitas itu sendiri menjadi instrumen yang harus diajarkan kepada semua guru. Kepala sekolah harus memiliki titik acuan ke mana membangun pengetahuan tambahan bagi guru; dan mencegah masalah perilaku, baik antara guru dengan siswa maupun antara guru dengan orang tua siswa. Kepala sekolah harus secara pro-aktif mengajarkan keterampilan, prosedur, jadwal, konsekuensi, dan harapan; dan, pada akhirnya, mengembangkan rencana implementasi dengan mengidentifikasi keterampilan baru yang harus dikuasai guru di masa depan (Davis \& Thomas, 1989).

Proses mentoring juga harus diarahkan agar guru memiliki kompetensi dan pengetahuan baru untuk mengatasi masalah perilaku dengan orang lain di sekolah atau di kelas. Mengembangkan langkah-langkah keterampilan tertentu, melalui analisis tugas kerja, juga penting agar terlatih dalam menggunakan metode pengajaran yang proaktif. Hal ini dapat dilaksanakan dengan lebih efektif lagi, bila sistem informasi diterapkan di sekolah yang terintegrasi dengan aktivitas dan penjadwalan mentoring, terutama dengan melacak pola masalah perilaku sebagai bahan dalam mentoring guru (Halinger, 2003).

Selain itu, adanya dominasi budaya tertentu terhadap budaya lain di dalam satu komunitas, tak terkecuali dalam sebuah lembaga pendidikan, dapat mengakibatkan ketegangan yang berujung kepada konflik (Muhamad, 2011). Hal demikian sering terjadi akibat adanya penempatan yang tidak tepat, baik dalam identitas lokal dan nasional maupun universal, pada saat berinteraksi dan bersosialisasi. Seseorang tanpa adanya kesadaran yang lapang akan merasa benar sendiri dengan membawa dominasi identitas lokal kedalam komunitas yang multikultural (Murpy, 1990; dan Muhamad, 2011).

Dalam hal ini perlu paradigma kepemimpinan yang tepat agar dominasi budaya tertentu dalam sebuah komunitas 
yang beragam tidak terjadi. Pada kasus kepemimpinan dalam pendidikan, paradigma yang harus dibenahi adalah paradigma kepemimpinan yang bersifat hierarkis-otokratis menuju kepemimpinan yang berbasis kemitraan bersama, dalam naungan kepemimpinan pendidikan, dengan paradigma multikultural (Murpy, 1990).

Berdasarkan pada latar belakang pernyataan di atas, penelitian ini membahas mengenai peran administrator sekolah dalam mentoring guru di lingkungan multikultural dan pemberdayaan kepemimpinan profesional yang sesuai dengan kondisi sekolah masing-masing.

Permasalahan Penelitian. Kepala sekolah memiliki peran yang luas dalam pendidikan, mulai dari aktivitas mentoring hingga memperbaiki suasana lingkungan sekolah agar dapat berguna bagi seluruh guru dan siswa (Hoque \& Kamaluddin, 2014). Selain itu, pada sekolah dengan jumlah guru dari berbagai latar belakang budaya membutuhkan tingkat pengetahuan multikultural yang cukup agar mereka dapat bekerja secara tim dan membangun kualitas pendidikan di sekolah mereka. Dengan demikian, kepala sekolah harus mampu menjalankan kegiatan mentoring orientasi, terutama bagi guru baru dan siswa baru (McCleary, Crow \& Matthews, 2013).

Bahkan, pembinaan siswa atau mentoring siswa merupakan kegiatan yang bertujuan membuat siswa sadar akan manfaat mengerjakan tugas-tugas belajar mereka. Namun, dalam melakukan pembinaan dan pengembangan siswa, kepala sekolah seringkali terlalu sibuk dan kurang memperhatikan hak dan kewajiban siswa. Dengan demikian, dibutuhkan kepemimpinan profesional dalam manajemen kesiswaan, dimana tanggung jawab kepala sekolah ialah memetakan permasalahan dan kebutuhan siswa, dan kemudian menyatukan ke dalam program di sekolah (Klaine-Kracht, 1993).

Selanjutnya, mengenai pengelolaan keuangan menjadi aspek yang penting untuk meningkatkan kualitas pendidikan (Hani, 2012). Kepala sekolah seringkali menghadapi keterbatasan anggaran, dan harus mampu mengelola dan mengevaluasi keuangan sekolah untuk meningkatkan kompetensi guru dalam mengembangkan fasilitas sekolah. Dengan demikian, kepemimpinan profesional kepala sekolah sangat penting untuk dibangun agar mampu melakukan pengelolaan keuangan, menjaga kualitas pendidikan, kompetensi guru, dan juga fasilitas sekolah. Selanjutnya, kepemimpinan profesional terkait dengan aktivitas monitoring, yang juga sangat penting dalam mengembangkan guru dan siswa, sehingga tercapai kualitas kinerja sekolah (Pujayanti, 2006).

Permasalahan lainnya ialah terkait dengan upaya yang telah dilakukan oleh kepala sekolah dalam meningkatkan pengetahuan guru dan siswa. Secara umum, perencanaan pembelajaran harus dilaksanakan secara rasional dan sistematis untuk meningkatkan kualtias pendidikan (Arifin, 2010). Namun, seringkali sekolah tidak mampu mencapai dan memiliki standar akademik yang tinggi, dan juga kemampuan melakukan evaluasi belajar secara objektif dan berkelanjutan. Dengan demikian, permasalahan konstruksi pengetahuan menjadi komponen penting dalam kepemimpinan professional.

Permasalahan lainnya ialah terkait dengan lingkungan sekolah multikultural, dimana gaya kepemimpinan kepala sekolah memberikan pengaruh pada kompetensi guru dan kelancaran pendidikan (Murpy, 1990; dan Muhamad, 2011). Gaya kepemimpinan itu disebut professional, jika kepemimpinan itu terjadi pengurangan dalam prasangka. Hal ini membutuhkan kepemimpinan kepala sekolah dan partisipasi guru dalam mengatasi konflik dalam dunia pendidikan, sehingga perlu mengetahui kepemimpinan profesional dalam membangun budaya sekolah.

Kepemimpinan Profesional. Banyak definisi mengenai kepemimpinan yang dikemukakan oleh para pakar menurut sudut 
pandang masing-masing, tergantung pada perspektif yang digunakan. Kepemimpinan dapat didefinisikan berdasarkan penerapannya pada bidang militer, olahraga, bisnis, pendidikan, industri, dan bidangbidang lainnya. Dalam konteks ini, D.M. Billings \& J.A. Halstead (2015) menjelaskan bahwa kepemimpinan adalah pengaruh antarpribadi, yang dijalankan dalam suatu sistem dan situasi tertentu, serta diarahkan melalui proses komunikasi ke arah pencapain satu tujuan atau beberapa tujuan tertentu (Billings \& Halstead, 2015).

M.A. Khalifa, M.A. Gooden \& J.E. Davis (2016) juga mendefinisikan kepemimpinan sebagai usaha untuk mempengaruhi anggota kelompok agar mereka bersedia menyumbangkan kemampuannya lebih banyak dalam mencapai tujuan kelompok yang telah disepakati (Khalifa, Gooden \& Davis, 2016). Dengan demikian, dalam konteks pengertian kepemimpinan di atas, terdapat berberapa hal yang saling terkait, yaitu adanya unsur penggerak, orang yang digerakkan, komunikasi, tujuan organisasi, dan manfaat yang tidak hanya dinikmati oleh sebagian orang, melainkan untuk kepentingan umum.

Kepemimpinan dipandang sebagai kemampuan untuk mempengaruhi sebuah kelompok untuk mencapai suatu visi atau serangkaian tujuan tertentu (Kennedy \& Heineke, 2016). Selain itu, kepemimpinan merupakan proses mendorong dan membantu orang lain untuk bekerja dengan antusias untuk mencapai tujuan (Jacobs, Beck \& Crowell, 2014). Sementara itu, J.W. Richardson et al. (2016) melihat kepemimpinan sebagai proses mengarahkan, membimbing, mempengaruhi, atau mengawasi pikiran, perasaan, dan tindakan (Richardson et al., 2016). Dalam konteks sekolah, M. Sahin \& A.L. White (2015) menjelaskan kepemimpinan, sebagai berikut:

Leadership, in the context of a school, help bring meaning and asense of purpose to the relationship between the leader, the staff, the students, the parents, and the wider school community. Leadership is not only a matter of what a leader does, but how a leader makes people feel about them-selves in the work situation and about the organisation itself (Sahin \& White, 2015).

Sementara itu, profesional didefinisikan sebagai kesiapan melaksanakan pekerjaan, dan selanjutnya mengabdikan diri karena ia merasa terpanggil untuk menyelesaikan pekerjaan (Scott et al., 2013). Profesionalisme, menurut S.P. Gordon \& E.A. Ronder (2016), merupakan motivasi instrinsik sebagai pendorong untuk mengembangkan dirinya ke arah perwujudan profesional (Gordon \& Ronder, 2016).

Kualitas profesionalisme kepala sekolah, yang didukung oleh kompetensi, ialah: (1) keinginan menampilkan perilaku yang mendekati standar ideal; (2) meningkatkan diri dan memelihara citra profesi; (3) keinginan untuk senantiasa mengejar kesempatan pengembangan profesional yang dapat meningkatkan dan memperbaiki kualitas pengetahuan dan ketrampilan; (4) mengejar kualitas dan cita-cita dalam profesi; serta (5) memiliki kebanggaan dalam profesinya (Mulyasa, 2003).

Menurut M.M. Atwater, M. Russell \& M. Butler eds. (2013), seseorang dianggap profesional bila mereka dipersiapkan khusus untuk suatu bidang pekerjaan tertentu, dan bukan karena orang tersebut tidak memperoleh pekerjaan lain (Atwater, Russell \& Butler eds., 2013). Secara keseluruhan, profesional didefinisikan sebagai penguasaan substansi pengetahuan, keterampilan teknis, dan keahlian khusus sesuai dengan bidang tugasnya masing-masing.

Selanjutnya, profesionalisme juga berkaitan dengan monitoring dan evaluasi. Monitoring adalah proses pengumpulan dan analisis informasi (berdasarkan indikator yang sudah ditetapkan) mengenai kegiatan program atau kegiatan sekolah, sehingga dapat dilakukan tindakan koreksi untuk 
penyempurnaan program atau kegiatan sekolah selanjutnya (Sergiovani, 1991). Evaluasi adalah proses penilaian pencapaian tujuan dan pengungkapan kinerja kepala sekolah untuk memberikan umpan balik bagi peningkatan kualitas kinerja program atau kegiatan sekolah mendatang. Manakala laporan merupakan catatan hasil dari monitoring dan evaluasi program, atau kegiatan sekolah, dalam bentuk kualitatif atau kuantitif berdasarkan pada hasil pengamatan dan evaluasi yang dilakukan dengan menggunakan instrumen yang dibuat (McEwan, 2002; dan Mulyasa, 2003).

Dalam kaitannya dengan pendidikan multicultural, M.N. Ovando \& M.B. Trube (2014) mengidentifikasi ada lima dimensi pendidikan multikultural, yang diperkirakan dapat membantu guru dalam mengimplementasikan beberapa program yang mampu merespon terhadap perbedaan pelajar atau siswa, yaitu:

Pertama, dimensi integrasi isi/materi (content integration). Dimensi ini digunakan oleh guru untuk memberikan keterangan dengan "poin kunci" pembelajaran, dengan melakukan refleksi materi yang berbeda-beda. Secara khusus, para guru menggabungkan kandungan materi pembelajaran kedalam kurikulum dengan beberapa cara pandang yang beragam.

Kedua, dimensi konstruksi pengetahuan (knowledge construction). Suatu dimensi dimana para guru membantu siswa untuk memahami beberapa perspektif dan merumuskan kesimpulan yang dipengaruhi oleh disiplin pengetahuan yang mereka miliki. Dimensi ini juga berhubungan dengan pemahaman para pelajar terhadap perubahan pengetahuan yang ada pada diri mereka sendiri.

Ketiga, dimensi pengurangan prasangka (prejudice reduction). Guru melakukan banyak usaha untuk membantu siswa dalam mengembangkan perilaku positif tentang perbedaan kelompok. Sebagai contoh, ketika anak-anak masuk sekolah dengan perilaku negatif dan memiliki kesalahpahaman terhadap ras atau etnik yang berbeda dan kelompok etnik lainnya, pendidikan dapat membantu siswa mengembangkan perilaku intergroup yang lebih positif, penyediaan kondisi yang mapan, dan pasti.

Keempat, dimensi pendidikan yang sama/adil (equitable pedagogy). Dimensi ini memperhatikan cara-cara dalam mengubah fasilitas pembelajaran, sehingga mempermudah pencapaian hasil belajar pada sejumlah siswa dari berbagai kelompok. Strategi dan aktivitas belajar yang dapat digunakan, sebagai upaya memperlakukan pendidikan secara adil, antara lain dengan bentuk kerjasama (cooperatve learning), dan bukan dengan cara-cara yang kompetitif (competition learning).

Kelima, dimensi pemberdayaan budaya sekolah dan struktur sosial (empowering school culture and social structure). Dimensi ini penting dalam memperdayakan budaya siswa yang dibawa ke sekolah, yang berasal dari kelompok yang berbeda (Ovando \& Trube, 2014).

\section{METODE PENELITIAN}

Penelitian ini menggunakan pendekatan kuantitatif yang berbentuk asosiatif (Usman, 2008; Sukardi, 2011; dan Creswell, 2016).

Hal ini ditujukan untuk mengetahui pengaruh peran administrator sekolah dalam memfasilitasi mentoring guru di lingkungan multikultural dan pemberdayaan kepemimpinan. Lokasi penelitian dilakukan di sejumlah SMA (Sekolah Menengah Atas) di Jakarta. Objek yang diteliti adalah kegiatan kepala sekolah dalam membimbing guru. Untuk menjawab tujuan penelitian tersebut, maka digunakan metode statistik deskriptif (Martono, 2010; dan Creswell, 2016).

Data terdiri dari kepala sekolah, guru, orang tua siswa, dan siswa. Mereka mengisi kuesioner dan menjelaskan mengenai demografi mereka. Data dikumpulkan dari sekolah-sekolah di wilayah Jakarta Selatan. Untuk itu, digunakan statistik 
Tabel 1:

Karakteristik Responden

\begin{tabular}{|c|c|c|}
\hline \multirow{2}{*}{ Responden } & \multicolumn{2}{|c|}{ Total } \\
\hline & Orang & $\%$ \\
\hline \multicolumn{3}{|l|}{ Responden berdasarkan gender: } \\
\hline Pria & 89 & $44.5 \%$ \\
\hline Wanita & 111 & $55.5 \%$ \\
\hline \multicolumn{3}{|l|}{ Responden berdasarkan jenis pekerjaan: } \\
\hline Guru & 97 & $48.5 \%$ \\
\hline Kepala Sekolah & 29 & $14.5 \%$ \\
\hline Administrasi Sekolah & 26 & $13 \%$ \\
\hline PNS/Polri/TNI (Pegawan Negeri Sipil/Polisi/Tentara Indonesia) & 21 & $10.5 \%$ \\
\hline BUMN (Badan Usaha Milik Negara) & 13 & $6.5 \%$ \\
\hline Wiraswasta & 14 & $7 \%$ \\
\hline \multicolumn{3}{|l|}{ Responden berdasarkan usia: } \\
\hline $25-30$ Tahun & 15 & $7.5 \%$ \\
\hline $30-35$ Tahun & 49 & $24.5 \%$ \\
\hline $35-40$ Tahun & 87 & $43.5 \%$ \\
\hline $40-45$ Tahun & 25 & $12.5 \%$ \\
\hline $45-50$ Tahun & 16 & $8 \%$ \\
\hline$>50$ Tahun & 8 & $4 \%$ \\
\hline \multicolumn{3}{|l|}{ Responden berdasarkan tingkat pendidikan: } \\
\hline SD/SMP (Sekolah Dasar/Sekolah Menengah Pertama) & - & - \\
\hline SMA (Sekolah Menengah Atas) & 9 & $4.5 \%$ \\
\hline Diploma dan Sarjana (D3 dan S1) & 154 & $77 \%$ \\
\hline Magister dan Doktor (S2 dan S3) & 37 & $18.5 \%$ \\
\hline
\end{tabular}

deskriptif karena dianggap sebagai cara tepat mendeskripsikan data yang telah tersedia secara apa adanya dan tanpa bermaksud untuk menyimpulkan secara umum (Simon \& Johnson, 2013).

Sedangkan untuk menjawab tujuan penelitian selanjutnya, penelitian ini menggunakan metode kuantitatif (Martono, 2010; dan Creswell, 2016). Metode tersebut bertujuan mengolah atau menganalisis data dengan angka-angka atau rumus-rumus perhitungan tertentu, untuk kemudian dianalisis sesuai dengan masalah yang diteliti dengan menggunakan software stata 12 (Martono, 2010; dan Creswell, 2016).

\section{HASIL DAN PEMBAHASAN}

Karakteristik Responden. Untuk menjawab rumusan masalah penelitian, maka dikumpulkan data dari kepala sekolah, guru, orang tua siswa, dan siswa. Mereka mengisi kuesioner dan menjelaskan mengenai demografi mereka. Data dikumpulkan dari sekolah-sekolah di wilayah Jakarta Selatan. Selanjutnya, data yang terkumpul diringkas untuk memperoleh gambaran karakteristik responden, yang terdiri dari gender, jenis pekerjaan, usia, dan tingkat pendidikan.

Responden berjumlah 200 orang, yang terdiri dari guru, kepala sekolah, dan orang tua siswa pada SMA (Sekolah Menengah Atas) di Jakarta Selatan, yang dapat diberikan gambarannya pada tabel.1.

Berdasarkan pada tabel 1, diketahui bahwa sebagian besar responden, berdasarkan gender, adalah wanita dengan jumlah 111 orang $(55.5 \%)$ dan pria 89 responden $(44.5 \%)$. Pekerjaan mereka kebanyakan adalah guru sebanyak 97 orang (48.5\%); kepala sekolah sebanyak 29 orang $(14.5 \%)$; administrasi sekolah sebanyak 26 orang (13\%); PNS/Polri/TNI atau Pegawai Negeri 
Sipil/Polisi/Tentara Indonesia sebanyak 21 orang (10.5\%); BUMN atau Badan Usaha Milik Negara sebanyak 13 orang $(6.5 \%)$; dan wiraswasta sebanyak 14 orang (7\%).

Sedangkan berdasarkan usia, responden berusia antara 35-40 tahun sebanyak 87 orang (43.5\%); usia antara 30-35 tahun sebanyak 49 orang $(24.5 \%)$; usia antara 40 45 tahun sebanyak 25 orang (12.5\%); usia antara 45-50 tahun sebanyak 16 orang (8\%); usia antara 25-30 tahun sebanyak 15 orang (7.5\%); dan usia $>50$ tahun sebanyak 8 orang (4\%).

Sedangkan responden berdasarkan tingkat pendidikan, diperoleh tingkat pendidikan tinggi, yakni Diploma dan Sarjana (D3 dan S1) sebanyak 154 orang (77\%); kemudian tingkat pendidikan Magister dan Doktor (S2 dan S3) sebanyak 37 orang (18.5\%); dan tingkat pendidikan SMA (Sekolah Menengah Atas) sebanyak 9 orang (4.5\%).

Hasil Model Penelitian. Model bernilai keseluruhan 6.28 dibandingkan dengan residual .29. Artinya, model yang diusulkan dianggap sangat baik. Selanjutnya, diperoleh $R$-squared 0.7188 . Artinya, proporsi varians dalam variabel dependen (kepemimpinan profesional) yang dapat dijelaskan oleh variabel independen (peran kepala sekolah, aktivitas mentoring, dan situasi multikultural mereka di sekolah). Seluruh variabel ini merupakan ukuran kekuatan hubungan dan tidak mencerminkan sejauh mana variabel independen tertentu dikaitkan dengan variabel dependen.

Pada peran kepala sekolah, mereka memiliki peran terbesar dalam "pengelolaan keuangan" $=.2113687$. Selanjutnya, pada "aktivitas mentoring", mereka memiliki kegiatan mentoring paling aktif dalam "membina guru dan siswa" $=.4159283$; yang diikuti oleh "kegiatan mentoring orientasi, terutama bagi guru baru dan siswa baru" = 1487102. Lihat tabel 2.

Pada materi belajar dengan konten multikulturalisme diperoleh tingkat partisipasi kepala sekolah, yang memiliki nilai sama, antara "pengelolaan pengetahuan" $=.3176289$ dan "pencegahan konflik", yang ditandai dengan kemampuan mengatasi prasangka antara guru dan siswa $=.3060302$. Sedangkan peran kepala sekolah dalam multikulturalisme ialah "keaktifan dalam pengelolaan budaya", yang dianggap masih rendah $=.1731904$. Peran kepala sekolah dalam "keuangan" lebih besar daripada "kepegawaian", ditandai dengan nilai t-test yang diperoleh dari analisis Stata (Martono, 2010; dan Creswell, 2016), yaitu 3.12 > 1.91.

Pada "aktivitas mentoring" yang dilakukan kepala sekolah, diperoleh nilai terbesar yaitu pada sub-variabel "pembinaan guru dan siswa", "pemberian pengetahuan multikultural", dan "pengurangan prasangka pada kelompok lain", yakni berturut-turut 5.73, 4.42, dan 4.19.

\section{Pertama, Kepemimpinan Profesional} dalam Manajemen Kesiswaan. Tanggung jawab kepala sekolah, secara garis besar, yang berhubungan dengan manajemen kesiswaan adalah memberikan layanan kepada siswa dengan memenuhi kebutuhan siswa secara efektif dan efisien. Adapun kegiatan yang sering dilakukan oleh kepala sekolah, dalam manajemen kesiswaan, dapat dikelompokkan menjadi tiga bagian utama, yaitu: (1) kegiatan penerimaan siswa; (2) pembinaan siswa; dan (3) pemantapan kegiatan yang harus dilakukan oleh siswa melalui program di sekolah ( $c f$ Heck, Larsen \& Marcoulides, 1990; Hoy \& Sabo, 1998; Mulyasa, 2003; dan Ovando \& Trube, 2014).

Kegiatan lainnya yang berkaitan dengan manajemen kesiswaan ialah pembinaan siswa. Pembinaan siswa merupakan layanan mentoring kepada siswa, baik didalam maupun di luar jam pelajarannya di kelas. Dalam pembinaan siswa dilaksanakan dengan menciptakan kondisi untuk memotivasi dan membuat siswa sadar akan tugas-tugas belajar mereka. Dalam hal ini, langkah-langkah yang dilakukan oleh seorang kepala sekolah adalah memberikan orientasi kepada siswa baru, mengatur dan 
Tabel 2:

Hasil Pengolahan Variabel Dependen dan Independen Menggunakan Stata 12

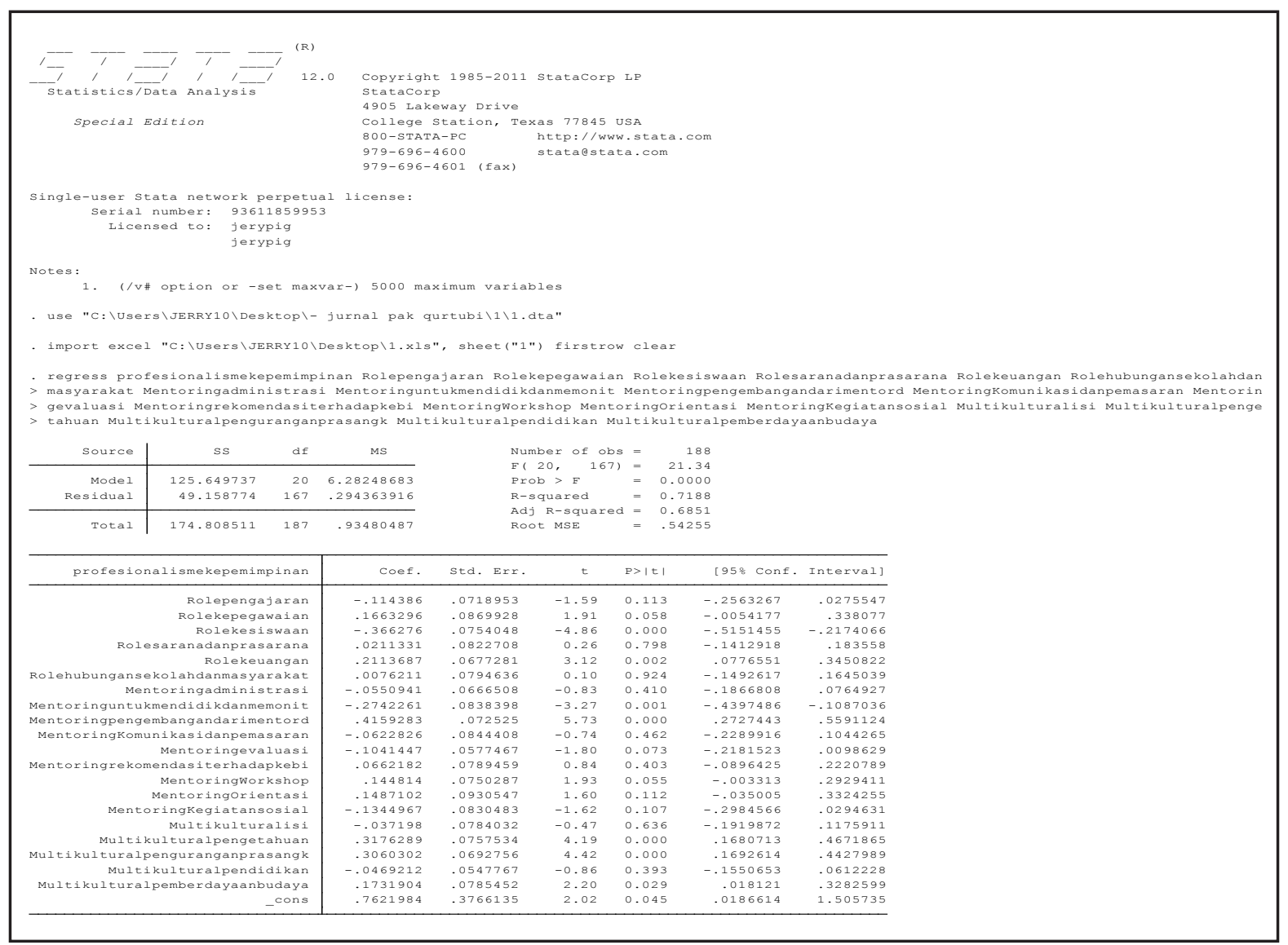

mencatat kehadiran siswa, mencatat prestasi dan kegiatan yang diraih dan dilakukan oleh siswa, dan mengatur disiplin siswa selaku peserta didik di sekolah ( $c f$ Dagett, 2005; Nugroho, 2006; Billings \& Halstead, 2015; dan Sumarsono, 2016).

Dalam melakukan pembinaan dan pengembangan siswa, kepala sekolah senantiasa memperhatikan hak dan kewajiban siswa, yaitu: (1) mendapat perlakuan sesuai dengan bakat, minat, dan kemampuan mereka; (2) hak untuk memperoleh pendidikan agama, sesuai dengan agama yang dianutnya; serta (3) hak untuk mengikuti program pendidikan yang bersangkutan atas dasar pendidikan berkelanjutan, baik untuk mengembangkan kemampuan diri maupun untuk memperoleh pengakuan tingkat pendidikan tertentu yang telah dibakukan dan sebagainya (Gorton \& Schneider, 1991;
Sallis, 1993; dan Mulyasa, 2003).

Selain hak-hak tersebut, siswa juga memiliki kewajiban untuk ikut menanggung biaya penyelenggaraan pendidikan, kecuali siswa yang dibebaskan dari kewajiban tersebut sesuai dengan peraturan yang berlaku; menghormati tenaga pendidik; dan siswa juga berkewajiban untuk mematuhi peraturan yang berlaku (Uben \& Hughes, 1992; James \& Peter, 1998; Kunandar, 2009; dan Richardson et al., 2016).

Kedua, Kepemimpinan Profesional dalam Pengelolaan Keuangan. Kepala sekolah berfungsi sebagai administrator pendidikan, yang berarti bahwa untuk meningkatkan mutu sekolahnya, seorang kepala sekolah dapat memperbaiki dan mengembangkan fasilitas sekolah, misalnya gedung, perlengkapan atau peralatan, dan lain-lain yang tercakup dalam bidang administrasi pendidikan (Soutworth, 2002; 
Halinger, 2003; dan Hani, 2012). Lalu, jika kepala sekolah berfungsi sebagai supervisor pendidikan, ianya berarti bahwa usaha peningkatan mutu dapat pula dilakukan dengan cara peningkatan mutu guru-guru dan seluruh staf sekolah, misalnya melalui rapatrapat, observasi kelas, perpustakaan, dan lain sebagainya.

Khusus yang berkenaan dengan pengelolaan keuangan, bahwa untuk tercapainya peningkatan kompetensi guru tidak lepas dari faktor biaya. Seberapa besar sekolah dapat mengalokasikan anggaran peningkatan kompetensi guru, tentunya akan mempengaruhi terhadap tingkat kompetensi para gurunya. Oleh karena itu, kepala sekolah seyogyanya dapat mengalokasikan anggaran yang memadai bagi upaya peningkatan kompetensi guru (Uben \& Hughes, 1992; Mulyasa, 2003; dan Pujayanti, 2006).

\section{Ketiga, Kepemimpinan Profesional} dalam Koordinasi untuk Mendidik dan Memonitor Kegiatan. Kepala sekolah yang profesional adalah seorang pimpinan yang terus-menerus melakukan perencanaan pembelajaran yang baik, dan berusaha pula mengaktualisasikan rencana tersebut dengan memanfaatkan potensi yang ada, dengan melakukan evaluasi kebijakan (Halinger, 2003; Tondok \& Andarika, 2004; dan Usman, 2007). Dengan demikian, kesalahankesalahan manajerial yang terjadi dapat diminimalisasi, sehingga tidak terjadi lagi di masa mendatang.

Kepala sekolah, sebagai kunci pendorong kemajuan sekolah, bertanggung jawab dalam meningkatkan akuntabilitas keberhasilan siswa dan programnya. Agar otonomi pendidikan berhasil dengan baik, kepemimpinan kepala sekolah harus mampu berperan sesuai dengan tugas, wewenang, dan tanggung jawabnya. Kepala sekolah harus siap memimpin kelompok, dengan pendelegasian tugas dan wewenang. Tanggung jawab tersebut termasuk menggerakan seluruh potensi sekolah secara optimal untuk mencapai tujuan (Dagett,
2005; Mulyasa, 2005; Arifin, 2010; Rahayu, Sutama \& Narimo, 2014; dan Wangke, 2014).

Keempat, Kepemimpinan Profesional dalam Pengembangan Diri Mentor dan Siswa. A.P. Santamaría et al. (2016) menyebutkan bahwa pada level manajemen puncak, kemampuan didalam melihat sesuatu secara keseluruhan, yang kemudian dapat merumuskannya, seperti dalam mengambil keputusan, menentukan kebijakan, dan lainlain, merupakan hal yang sangat penting (Santamaría et al., 2016).

Dalam konteks ini, penilaian kinerja manajerial kepala sekolah dapat dilakukan melalui monitoring, evaluasi, dan pelaporan pada setiap program sekolah (cf Mulyasa, 2003; Dagett, 2005; dan Arifin, 2010).

\section{Kelima, Kepemimpinan Profesional} dalam Konstruksi Pengetahuan. Temuan menunjukan bahwa kepala sekolah berperan besar dalam terbentuknya pengetahuan organisasi dan pengetahuan kelas. Pengetahuan baru harus terus dikumpulkan dan masuk dalam perencanaan pembelajaran. Perencanaan pembelajaran merupakan penerapan yang rasional dari analisis sistematis proses perkembangan pendidikan dengan tujuan agar pendidikan itu lebih efektif dan efisien, sesuai dengan tuntutan kebutuhan dan tujuan para murid dan masyarakat (Sahin \& White, 2015).

Hal ini membutuhkan kemampuan kepala sekolah dalam mengorganisasikan kegiatan pembelajaran, melalui manajemen partisipatif dan kegiatan inovatif. Selain itu, perencanaan juga berkaitan dengan penetapan standar akademik yang tinggi dan kegiatan evaluasi belajar yang objektif dan berkelanjutan (Mulyasa, 2003; Dagett, 2005; Arifin, 2010; dan Scott et al., 2013).

Keenam, Kepemimpinan Profesional dalam Pengurangan Prasangka.

Berdasarkan temuan menunjukan bahwa kepala sekolah harus menggunakan gaya kepemimpinan yang dapat mengakomodir semua pemangku kepentingan dan meminimalkan kesenjangan dan prasangka 
didalam pemangku kepentingan tersebut. Gaya kepemimpinan kepala sekolah dapat menumbuh-suburkan kreativitas, sekaligus mendorong peningkatan kompetensi guru (Dagett, 2005; Mulyasa, 2005; dan Atwater, Russell \& Butler eds., 2013).

Dalam teori kepemimpinan, setidaknya terdapat orientasi tugas pendidikan dan orientasi kesejahteraan guru (Usman, 2008; dan Sukmawati, 2009). Dalam rangka untuk meningkatkan kompetensi guru, kepala sekolah harus mampu menyeimbangkan gaya kepemimpinan tersebut secara tepat dan fleksibel, disesuaikan dengan kondisi dan kebutuhan yang ada.

K. Hoque \& M.A. Kamaluddin (2014) menyebutkan bahwa kepemimpinan seseorang sangat berkaitan dengan kepribadian; dan kepribadian kepala sekolah sebagai pemimpin akan tercermin untuk menjadi teladan dan mampu mengambil keputusan yang mengarahkan guru agar melalui orientasi yang tepat (Hoque \& Kamaluddin, 2014).

Ketujuh, Kepemimpinan Profesional dalam Membangun Budaya Sekolah. Dalam pandangan manajemen pendidikan, kualitas pendidikan di sekolah banyak dipengaruhi oleh kepemimpinan kepala sekolah, yang bertanggung jawab dalam menjalankan fungsi dan peran kepemimpinannya secara profesional (McEwan, 2002; Mulyasa, 2003; dan Khalifa, Gooden \& Davis, 2016).

Kepala sekolah, dalam menjalankan kepemimpinan pendidikan, perlu: (1) melibatkan guru-guru dan staf dalam aktivitas penyelesaian masalah dengan menggunakan metode ilmiah atau scientific dan prinsip proses pengawasan mutu dengan statistik; (2) mengumpulkan aspirasi mereka tentang sesuatu dan bagaimana sebuah masalah ditangani; (3) memahami keinginan untuk perbaikan bagi guru-guru untuk memperbaiki gaya kepemimpinan; (4) membangun komunikasi dan melibatkan setiap orang di sekolah; (5) meningkatkan kompetensi dan keterampilan, sehingga mampu mengatasi konflik dan negosiasi dengan lebih cepat; (6) memperluas makna mutu dan pembelajaran melalui partisipasi tim, proses manajemen, pelanggan, komunikasi, dan kepemimpinan; serta (7) menumbuhkan otonomi dan mengatasi resiko kerja (Halinger, 2003; Mulyasa, 2005; dan Jacobs, Beck \& Crowell, 2014).

\section{KESIMPULAN}

Berdasarkan pada analisis dan pembahasan di atas ditemukan bahwa halhal yang mempengaruhi dalam peningkatan profesionalisme kepala sekolah pada berbagai SMA (Sekolah Menengah Atas) di Jakarta Selatan adalah pada kemampuan kepala sekolah dalam menumbuhkan kepemimpinan profesional di lingkungan kerja. Kepala sekolah harus aktif dalam peran pembinaan (mentoring) kesiswaan dan guru; pengelolaan keuangan; koordinasi kegiatan pendidikan; serta pengembangan guru dan siswa. Hal ini ditunjukkan dalam kesiapan mereka menjalankan kepemimpinan profesional dalam konstruksi pengetahuan (knowledge construction), pengurangan prasangka (prejudice reduction), dan pemberdayaan budaya pendidikan di lingkungan sekolah.

Secara keseluruhan, profesionalisme telah menjadi istilah yang makin penting dalam aktivitas sekolah. Profesionalisme dalam kepemimpinan pendidikan menjadi instrumen dan kerangka penyiapan sumber daya manusia di dunia kerja dan di masyarakat, baik pada tataran manajerial, proses pendidikan maupun pembelajaran. Adanya perbedaan kultur dalam organisasi menjadi tugas pemimpin untuk mengedukasi anggota organisasi tersebut. Hal ini berlaku pula pada sekolah.

Kepala sekolah berperan besar dalam menumbuhkan kepemimpinan profesional untuk mengatasi perbedaan budaya kerja dan tradisi pengajaran melalui strategi mentoring yang tepat. Oleh karena itu, kepala sekolah 
harus menyadari posisi dan perannya agar sekolah yang dipimpinnya mengalami kemajuan, sejalan dengan semangat dan kebutuhan zaman. ${ }^{1}$

\section{Referensi}

Arifin. (2010). "Konsep Perencanaan, Pendekatan, dan Model Perencanaan Pendidikan". Tersedia secara online di: https://drarifin.wordpress. com/2010/07/15/konsep-perencanaan-pendekatandan-model-perencanaan-pendidikan/ [diakses di Ciputat, Indonesia: 15 Februari 2016].

Atwater, M.M., M. Russell \& M. Butler [eds]. (2013). Multicultural Science Education: Preparing Teachers for Equity and Social Justice. London: Springer Science \& Business Media.

Billings, D.M. \& J.A. Halstead. (2015). Teaching in Nursing: A Guide for Faculty. London: Elsevier Health Sciences.

Creswell, John W. (2016). Research Design: Pendekatan Kualitatif, Kuantitatif, dan Campuran. Yogyakarta: Pustaka Pelajar, Terjemahan, edisi keempat.

Dagett, W.R. (2005). "Successful School: From Research to Action Plan". Tersedia secara online di: http://www.quality.cr.k12.ia.us/Resources/ SuccessfulSchools Daggett 05.pdf [diakses di Ciputat, Indonesia: 15 Februari 2016].

Davis, G.A. \& M.A. Thomas. (1989). Effective Schools and Effective Teachers. Boston: Allyn and Bacon.

Farisi, M. Madzhub. (2012). "Peran Kepala Sekolah dalam Peningkatan Motivasi Kerja Guru". Tersedia secara online di: http://download.portalgaruda.org/ article.php? article $=122904 \& \mathrm{val}=5556$ [diakses di Ciputat, Indonesia: 25 Januari 2017].

Gordon, S.P. \& E.A. Ronder. (2016). "Perceptions of Culturally Responsive Leadership: Inside and Outside of a Principal Preparation Program" in IJER: International Journal of Educational Research, Vol.25, No.2, pp.125-136.

Gorton, R.A. \& G.T. Schneider. (1991). SchoolBased Leadership: Challenges and Opportunities. Dubuque: Wim C. Brown Company Publisher.

\footnotetext{
${ }^{1}$ Pernyataan: Dengan ini, saya menyatakan bahwa artikel ini, beserta seluruh isinya, benar-benar karya saya sendiri dan saya tidak melakukan penjiplakan atau pengutipan dengan cara yang tidak sesuai dengan etika keilmuan yang berlaku dalam masyarakat keilmuan. Artikel ini juga belum dikirimkan, tidak sedang direviu, serta tidak akan diterbitkan oleh jurnal ilmiah lainnya. Saya siap menanggung resiko, berupa sanksi akademik, apabila di kemudian hari ternyata apa-apa yang saya buat dalam pernyataan ini tidak benar.
}

Halinger, P. (2003). "Leading Education Change: Reflections on the Practice of Intructional Leadership" in Cambridge Journal of Education, 33(3), pp.35-70.

Hani, Ami Amalia. (2012). "Pengelolaan Keuangan Pendidikan". Tersedia secara online di: https:// amiamaliahanii.wordpress.com/2012/05/30/ pengelolaan-keuangan-pendidikan/ [diakses di Ciputat, Indonesia: 8 Februari 2017].

Heck, R.H., T.J. Larsen \& G.A. Marcoulides. (1990). "Instructional Leadership and School Achievement: Validation of a Causal Model" in Educational Administration Quarterly, 26(2), pp.94-125.

Hoque, K. \& M.A. Kamaluddin. (2014). Human Resource Managers in Education: Their Roles in School Effectiveness. London: Routledge.

Hoy, W.K. \& D.J. Sabo. (1998). Quality Middle Schools: Open and Healthy. New York: Corwin Press, Inc.

Jacobs, J., B. Beck \& L. Crowell. (2014). “Teacher Leaders as Equity-Centered Change Agents: Exploring the Conditions that Influence Navigating Change to Promote Educational Equity" in Professional Development in Education, 40(4), pp.576-596.

James, C.F. \& P. Peter. (1998). "The Practice of Educational Marketing in School" in C.F. James \& P. Peter [eds]. Educational Management Strategy, Quality, and Resources. Philadelphia: Open University Press.

Kennedy, A.S. \& A.J. Heineke. (2016). "Preparing Urban Educators to Address Diversity and Equity through Field-Based Teacher Education: Implications for Program Design" in Handbook of Research on Professional Development for Quality Teaching and Learning. London: Routledge, pp.437-448.

Khalifa, M.A., M.A. Gooden \& J.E. Davis. (2016). "Culturally Responsive School Leadership: A Synthesis of the Literature" in Review of Educational Research, 19(1), DOI 0034654316630383.

Klaine-Kracht, S.P. (1993). "Indirect Intructional Leadership: An Administrator's Choice" in Educational Administration Quarterly, 29(2), pp.187-212.

Kunandar. (2009). Guru Profesional: Implementasi Kurikulum Tingkat Satuan Pendidikan dan Sukses dalam Sertifikasi Guru. Jakarta: Rajawali Press.

Maisyaroh. (2016). "Membangun Budaya dan Iklim Sekolah di Era Global". Tersedia secara online di: http://ap.fip.um.ac.id/wp-content/ uploads/2016/03/45-Maisyaroh.pdf [diakses di Ciputat, Indonesia: 8 Februari 2017].

Martono, Nanang. (2010). Metode Penelitian Kuantitatif: Analisis Isi dan Analisis Data 
Sekunder. Jakarta: PT Raja Grafindo Persada.

McCleary, L.E., G.M. Crow \& L.J. Matthews. (2013). Leadership: A Relevant and Realistic Role for Principals. London: Routledge.

McEwan, E.K. (2002). 7 Steps to Effective Instructional Leadership. California: Corwin Press.

Muhamad, Fauzi. (2011). "Kepemimpinan Pendidikan Berbasis Multikultural: Solusi Penyelesaian Konflik Budaya dalam Institusi Pendidikan”. Tersedia secara online di: http://mufazi881. blogspot.co.id/2011/10/kepemimpinan-pendidikanberbasis.html [diakses di Ciputat, Indonesia: 8 Februari 2017].

Mulyasa, E. (2003). Menjadi Kepala Sekolah Profesional. Bandung: Remaja Rosdakarya.

Mulyasa, E. (2005). Menjadi Guru Profesional. Bandung: PT Remaja Rosdakarya.

Murpy, J. (1990). "Preparing School Admistrators for the Twenty-First Century: The Reform Agenda" in B. Mitchel \& L.L.Cuningham [eds]. Educational Leadership and Changing Contects of Families, Comonites, and Schools. Chicago: University of Chicago Press.

Nugroho, Bambang. (2006). "Reward dan Punishment" dalam Bulletin CiptaKarya. Jakarta: Departemen Pekerjaan Umum.

Ovando, M.N. \& M.B. Trube. (2014). "Capacity Building of Beginning Teachers from Alternative Certification Programs: Implications for Instructional Leadership" in JSL: Journal of School Leadership, Vol.10, No.4, pp.10-34.

Pujayanti, Ninik. (2006). "Peranan Kepala Madrasah sebagai Supervisor dalam Pengembangan Staf dan Kurikulum: Studi Kasus di SMP Negeri 11 Tangerang, Banten". Tesis Magister Pendidikan Tidak Diterbitkan. Semarang: PPs UNES [Program Pascasarjana, Universitas Negeri Semarang].

Rahayu, Sri, Sutama \& Sabar Narimo. (2014).

"Kepemimpinan Kepala Sekolah dan Kedisiplinan Guru SMPN Kota Surakarta" dalam Jurnal Manajemen Pendidikan, Vol.9, No.2, Juli, hlm.97-107. Tersedia secara online juga di: http:// download.portalgaruda.org/article.

p? article $=449708 \& \mathrm{val}=9528 \&$ title $=$ Kepemimpinan [diakses di Ciputat, Indonesia: 25 Januari 2017].

Richardson, J.W. et al. (2016). "Are Changing School Needs Reflected in Principal Job Ads?" in NASSP Bulletin, DOI 0192636516656797.

Sahin, M. \& A.L. White. (2015). “Teachers' Perceptions Related to Characteristics of a Professional Environment for Teaching" in Eurasia Journal of Mathematics, Science \& Technology Education, 11(3), pp.559-575.

Sallis, E. (1993). Total Quality Management in Education. London: Kogan Page, Ltd.

Santamaría, A.P. et al. (2016). Te Ara Hou: A New
Pathway for Leading Māori Success as Māori. London: Routledge.

Scott, D.E. et al. (2013). "Indigenous Principals' Perspectives on Leadership Development and Understanding the Principalship: An International Guide to Principal Preparation" in Advances in Educational Administration, Vol.19, pp.315-344.

Sergiovani, T.J. (1991). The Principalship: A Reflective Practice Prespective. Boston: Allyn and Bacon.

Simon, N.S. \& S.M. Johnson. (2013). "Teacher Turn Over in High-Poverty Schools: What We Know and Can Do" in Teachers College Record, 117, pp.1-36.

Sinaga, Muaraputra. (2015). "PTS: Upaya Meningkatkan Disiplin Guru dalam Kehadiran Mengajar di Kelas melalui Penerapan Reward and Punishment di SMP Satu Atap Negeri 2 Onanrunggu, Kecamatan Onanrunggu, Kabupaten Samosir, Semester II Tahun Ajaran 2014/2015". Tersedia secara online di: http:// www.smpsatapn2onanrunggu.sch.id/pts-upayameningkatkan-disiplin-guru [diakses di Ciputat, Indonesia: 25 Januari 2017].

Soutworth, G. (2002). "Intructional Leadership in School: Reflection and Empirical Evidence" in School Leadership and Management, 22(1), pp.73-92.

Suherman, Ade. (2016). "Pengaruh Budaya Sekolah dan Motivasi Kerja Guru terhadap Mutu Pendidikan". Tersedia secara online di: http:// adesuherman.blogspot.co.id/2011/06/pengaruhbudaya-sekolah-dan-motivasi.html [diakses di Ciputat, Indonesia: 25 Januari 2017].

Sukardi. (2011). Metodologi Penelitian Pendidikan: Kompetensi dan Praktiknya. Yogyakarta: Bumi Aksara.

Sukmawati, Meity. (2009). "Gaya Kepemimpinan Kepala Sekolah SMA Muhammadiyah 3 Tangerang". Tersedia secara online di: http:// www.gunadarma.ac.id/library/articles/graduate/ psychology/2009/Artikel 10505123.pdf [diakses di Ciputat, Indonesia: 25 Januari 2017].

Sumarsono, Raden Bambang. (2016). "Upaya Peningkatan Mutu Sekolah melalui Penguatan Peran Kepemimpinan Pembelajaran oleh Kepala Sekolah". Tersedia secara online di: http://ap.fip. um.ac.id/wp-content/uploads/2016/03/41-RadenBambang-Sumarsono.pdf [diakses di Ciputat, Indonesia: 25 Januari 2017].

Tondok, M.S. \& R. Andarika. (2004). "Hubungan antara Persepsi Gaya Kepemimpinan Transformasional dan Transaksional dengan Kepuasan Kerja Karyawan" dalam Jurnal PSYCHE, Vol.1, No.1, Desember. Tersedia secara online juga di: http://psikologi.binadarma.ac.id/ jurnal/jurnal_marcel_rita.pdf [diakses di Ciputat, Indonesia: 25 Januari 2017]. 
Trezna, Ichey. (2015). "Peran Masyarakat dalam Peningkatan Mutu Sekolah/Pendidikan”. Tersedia secara online di: http://www.kompasiana. com/ichey trezna/peran-masyarakat-dalampeningkatan-mutu-sekolah-pendidikan [diakses di Ciputat, Indonesia: 25 Januari 2017].

Uben, G.C. \& L.W. Hughes. (1992). The Principal: Creative Leadership for Effective School. Boston: Allyn and Bacon.

Usman, H. (2007). "Faktor-faktor yang Mempengaruhi Perilaku Kepala Sekolah" dalam Jurnal Tenaga Kependidikan, Vol.2, No.3, Desember. Tersedia juga secara online di: http://www.ziddu.com/download/4077925/ rFaktoryangmempengaruhiPerilakuKepala Sekolah.pdf.html [diakses di Ciputat, Indonesia: 25 Januari 2017].

Usman, H. (2008). Manajemen: Teori, Praktik, dan Riset Pendidikan. Jakarta: Bumi Aksara.

Wangke, H. (2014). "Peluang Indonesia dalam MEA" dalam Info Singkat Hubungan Internasional, 6(10), hlm.5-8.

Wilison, R. (2010). "What Make an Intructional Leader" in Phi Delta Kappan, 92(3), November, pp.66-69. 